\title{
Climate data and information needs of indigenous communities on reservation lands: insights from stakeholders in the Southwestern United States
}

\author{
Helen Fillmore ${ }^{1}$ (D) $\cdot$ Loretta Singletary ${ }^{2}$ (D)
}

Received: 24 July 2020 / Accepted: 24 September 2021 /Published online: 27 December 2021

(c) The Author(s) 2021

\begin{abstract}
Indigenous communities on reservation lands across the USA continue to demonstrate their leadership in climate resilience through active engagement in co-producing interdisciplinary solutions to adaptation. These initiatives, however, often ask Indigenous peoples to provide knowledge and resources to assist with adaptation efforts beyond their communities, which can limit their capacity to act locally. Trusting their expertise, we utilize a participatory research approach that asks tribal government employees, agriculturalists, researchers, and outreach professionals to prioritize the climate information and data they perceive as necessary to enhance the climate resilience of water resources of Indigenous communities. In doing so, this study provides empirical evidence specific to the climate adaptation needs of Indigenous communities on reservation lands in the arid southwestern USA. Study respondents prioritize climate information and data that serve to assess local climate change impacts, enhance food security, and integrate and protect the traditional knowledge of their communities. In this arid and predominantly rural region, respondents prioritize water quality data as their highest need followed by streamflow and air temperature data. They most frequently access their respective tribal government sources of climate information and data. These results indicate that localized climate data and information are highly prioritized. Future research and action to alleviate information and data gaps should account for the relevance, accessibility, and protection of these resources while prioritizing methods that ensure Indigenous sovereignty and self-determination rather than knowledge extraction.
\end{abstract}

Keywords Indigenous communities - Climate adaptation - Water resources · Traditional knowledge $\cdot$ Needs assessment

Loretta Singletary

singletaryl@unr.edu

Helen Fillmore

fillmoreh@unr.edu

1 Extension, University of Nevada-Reno, Reno, NV, USA

2 Extension and Department of Economics, University of Nevada-Reno, Reno, NV, USA 


\section{Introduction}

Warming atmospheric temperatures coincide with decreasing water availability in the southwestern USA, which compound aridity issues already associated with this desert region (Hoerling et al. 2019; MacDonald 2010; Miller et al. 2021; Seager et al. 2013; Udall and Overpeck 2017). Climate impacts on water resources include increasing severity and frequency of drought and/or monsoonal flood events, diminished annual snowpack, earlier snowmelt, and higher evapotranspiration rates (Fritze et al. 2011; Li et al. 2017; Miller and Piechota 2011). These changes pose unique adaptation challenges for Indigenous communities, as they threaten the complex interconnections between Indigenous people and the natural systems in which they coexist (Jantarasami et al. 2018; Mayer et al. 2019). Warming air temperatures may degrade habitat conditions necessary for sustaining culturally important native plants and wildlife, which threatens traditional agricultural and subsistence practices (Burnette et al. 2019; Elias et al. 2019; Redsteer et al. 2018). Declining water availability stymies the development of economic industries, such as irrigated commercial agriculture and rural tourism, and it may also limit regional capacity to sustainably meet water needs for population growth (Steele et al. 2018). Projected changes to climate and water resources pose significant threats to Indigenous communities as such changes will impact key infrastructure and economic sectors and threaten cultural resources and community health and well-being (Credo et al. 2019; Donatuto 2011; Mayer et al. 2019; Stanley et al. 2017).

Indigenous communities retain unique place-based interdependencies between their physical environments and the cultural, political, and spiritual makeup of their societies (Ellis and Perry 2020; Maldonado et al. 2016; Whyte 2018a). Shifts in physical environmental systems due to climatic changes will undoubtedly force shifts in social environmental systems, yet these unique inter-relationships may present opportunities for Indigenous communities to implement sustainable adaptation measures that originate in traditional knowledge (Long and Steel 2020; Thomas et al. 2018). That is, Indigenous communities are among the first to initiate and actively engage in climate adaptation initiatives across the USA (Cozzetto et al. 2013; Jantarasami et al. 2018). As compared to non-Indigenous communities, Indigenous communities have more readily recognized and acknowledged evidence of climate change impacts (Smith et al. 2014). This may be due-in part-to long-established relational ethics systems linked to the protection of ecological services and strong communal relationships inherent to Indigenous communities (Fillmore 2017; Martin et al. 2020). Both attributes provide a strong foundation for successfully carrying out community-based adaptation processes (Maldonado et al. 2016). Indeed, Indigenous recognition of climate change impacts on their communities may inspire and characterize future public policies that aim to mitigate or adapt to climate change impacts generally (Gurney et al. 2020).

As Indigenous communities continue to demonstrate proactive approaches to adaptation in the face of climate vulnerability, increasing efforts are underway to involve Indigenous communities and Indigenous traditional knowledge in climate adaptation research (Ford et al. 2018; Petzold et al. 2020). In a meta-analysis of climate adaption research involving Indigenous communities, Petzold et al. (2020) found that this body of research primarily focuses on environmental observations, environmental uses, governance, and cultural perspectives rather than capacity-building. Further, Indigenous communities increasingly call for research ethics protocols that ensure the avoidance of the inadvertent extraction, dissemination, and misappropriation of Indigenous traditional knowledge (Gautam et al. 
2013; Klenk et al. 2017). At a minimum, research protocols should maintain free, prior, voluntary, and informed consent of participants, give proper credit to participants engaged in the collaborative co-production of new knowledge, and tailor research protocols to be relevant to those communities who voluntarily participate in such research (Chief et al. 2016; Gettelsohn et al. 2018).

Participatory research methods aim to engage communities directly in co-identifying research goals and objectives, which help to ensure that subsequent research activities, questions, and findings are ultimately useful to support and inform local decisions (Chief et al. 2016; Kirkby et al. 2017; Klenk et al. 2017; Meadow et al. 2015; Reid 2016; Singletary and Sterle 2020). These methods align with Indigenous inherent rights of sovereignty and self-determination which are centered on the ability of community members, as research participants, to volunteer input at all stages of the research processes. Such research methods may also empower Indigenous communities to selfdetermine a role for traditional knowledge in their adaptation efforts, which may include protecting traditional knowledge from inadvertent and unintended uses (Brewer and Kronk Warner 2015; Cochran et al. 2013; Whyte 2018b). Emerging from participatory research methods and practices, community-based adaptation frameworks have proven particularly successful in empowering Indigenous communities to act locally (Dodman and Mitlin 2013; Kirkby et al. 2017; McNamara et al. 2020; Reid 2016). Specifically, through their direct involvement in scientific inquiry, Indigenous communities are encouraged to conceptualize, voice, and lead local action (Westoby et al. 2020).

\section{Methods}

\subsection{Purpose}

Utilizing a participatory research approach, we engaged with tribal government employees, agriculturalists, researchers, and outreach professionals at five annual Native Waters on Arid Lands Tribal Summits held in either Las Vegas or Reno, Nevada. Our study and survey question items featured were informed by small group discussions with participants of the first summit in 2015. Specifically, summit participants voiced a broad range of information and data needed to support their ongoing climate adaptation initiatives, including down-scaled climate prediction models as well as resources to protect any traditional knowledge they used in their adaptation plans. From these discussions, we developed this study to respond to two overarching research questions: (1) what climate data and information are needed to support climate adaptation on reservation lands? And (2) what are the most frequently accessed resources of climate data and information that support current climate adaptation planning on reservation lands?

\subsection{Survey instrument}

Information or knowledge gaps that 2015 summit attendees voiced during small group break-out discussion sessions were used to begin formulating question items related to general climate data and information needs. This listening approach-an important component of participatory research methods - supported the authors' development of a first draft of a survey. Developing survey question items informed by summit participants ensured that responses to the questions would be meaningful, relevant, and subsequently useful to 
the Indigenous communities represented. The authors then cross-referenced these question items with existing research literature related to community-based climate adaptation planning and climate impacts specific to the water resources of Indigenous communities on reservation lands in the southwestern USA (Bennett et al. 2014; Chief et al. 2014, 2016; Cochran et al. 2013; Cozzetto et al. 2013; Gautam et al. 2013; Maldonado et al. 2016). Additional information and data needs included in the survey were determined from guidelines set forth by the Tribal Climate Change Adaptation Planning Toolkit available through the US Climate Resilience Toolkit and Guidelines for Considering Traditional Knowledges in Climate Change produced by the Climate and Traditional Knowledges Workgroup in 2014. These specific resources are intended to provide Indigenous communities in the USA with tools and assistance in the climate change adaptation planning process (Climate and Traditional Knowledges Workgroup 2014; Institute for Tribal Environmental Professionals 2020).

An interdisciplinary panel of four faculty members with expertise in hydrologic science, atmospheric science, agricultural and applied economics, extension outreach, and survey methods reviewed drafts of the survey instrument. The purpose of these reviews was to improve the readability and clarity of question items and to identify any missing question items. We revised question items based on the feedback received from these reviews.

\subsection{Study area}

To define our study area, we use three US Geologic Survey (USGS) water resource regions delineated at 2-digit hydrologic unit codes as Great Basin, Upper Colorado, and Lower Colorado. We refer to this study area as a whole as the southwestern U.S., which spans several states including Arizona, California, Colorado, Idaho, Nevada, New Mexico, and Utah. Utilizing USGS water resource regions to delineate study area boundaries helps to address the complexity associated with water allocated for use through prior appropriation doctrine and water rights that are adjudicated at the watershed scale (Colby et al. 2005; Deol 2017; McNeeley 2017). Additionally, the ecological coherence within water resource regions, compared to state or other governmental boundaries, ensures that study participants exist within comparable environmental and climatological conditions.

We identified study participants as individuals living or working on reservation lands inhabited by 49 federally recognized tribes within the region. In the Upper Colorado and Lower Colorado water resource regions, reservation lands comprise nearly 43.6 million acres. In the Great Basin water resource region, reservation lands comprise nearly 2.1 million acres. Figure 1 illustrates the approximate location of these reservations within our study region noted by names of the 49 federally recognized tribes, referred to herein simply as Indigenous communities.

Studies surveying Indigenous communities at regional levels are rare-and reasonably so- due to the place-based nature of Indigenous cultures and the diversity of community experiences. Conducting research at a regional scale, however, is a burden of necessity, as it is important to assess needs and priorities in order to support collective climate adaptation initiatives. That is, both local and regional climate action in the USA interconnects with economic and political priorities and can be most effective when there is coherency of adaptation priorities at multiple geographical scales (Gurney et al. 2020). The challenge that we faced in pursuing this regional study is that while cumulative results reported may appear to homogenize the diverse perceptions, needs, experiences, and perspectives of survey respondents, we necessarily avoided comparing and contrasting individual tribes 


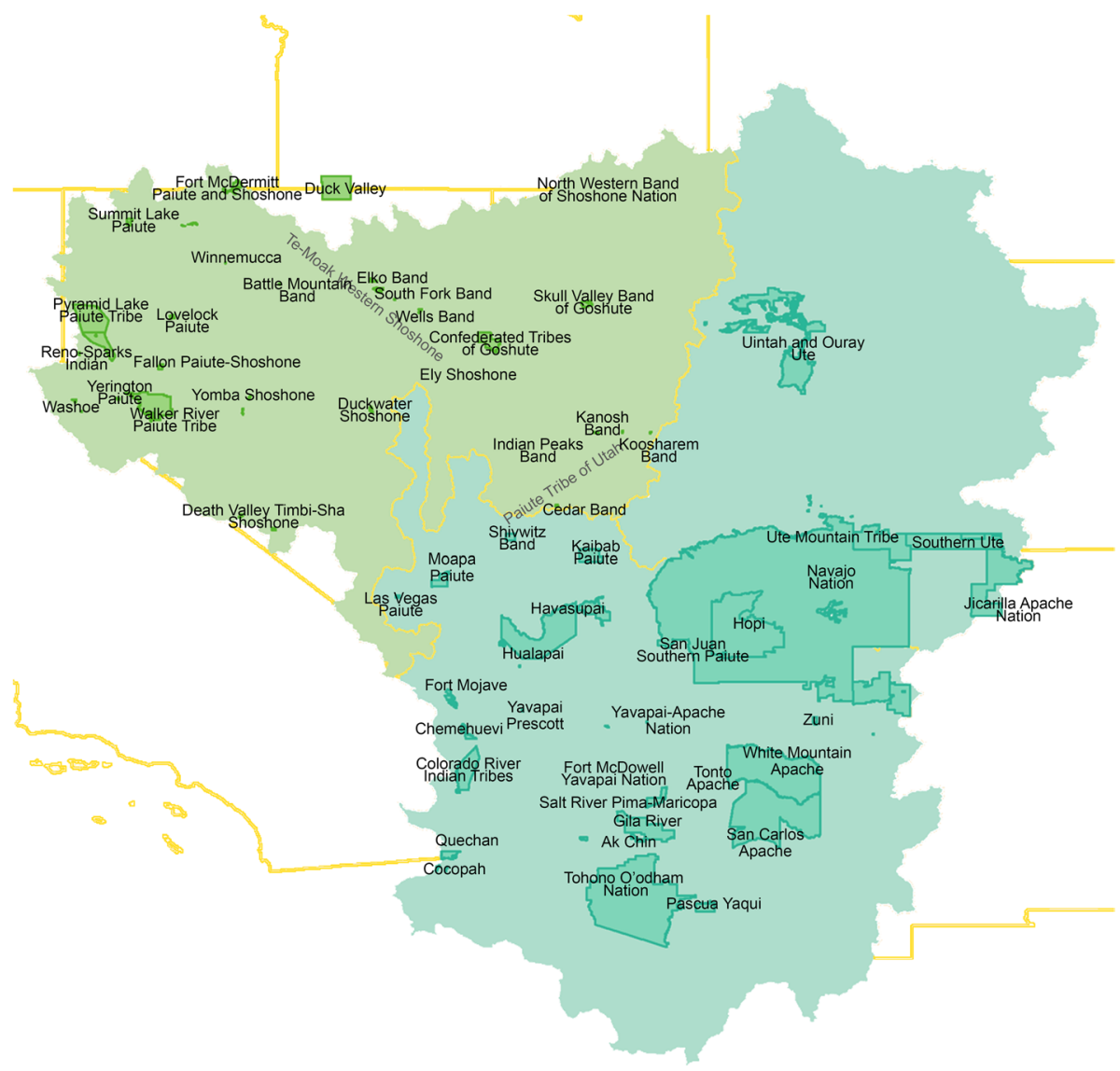

Fig. 1 Approximate location of reservation lands of the 49 federally recognized tribes [Indigenous communities] within the study region

and/or Indigenous communities in order to protect their anonymity and respect their right to data sovereignty. Instead, our study offers a regional assessment of perceived climate information and data needs and includes a cross-correlation analysis based on the three aggregated demographic variables representative of the individuals who participated in this study.

\subsection{Target population and survey sample recruitment}

As Indigenous communities on reservation lands in the arid southwestern USA are expert witnesses to both the challenges and opportunities surrounding climate adaptation of water resources vital to their existence, this study utilizes participatory research methods to assess, from their perspectives, climate information, and data necessary to facilitate adaptation. Specifically, we surveyed stakeholders who we defined for this study as individuals actively participating in climate adaptation initiatives on reservation lands and, as such, have experience with both challenges and opportunities surrounding such efforts. This population that includes tribal employees-such as community-based 
planners and water/land resource managers, agriculturalists, researchers, and outreach professionals - serve as key informants in identifying and prioritizing climate data and information needs of Indigenous communities, as they are uniquely familiar with the types of climate data and information currently accessible to them as well as information and data gaps that might impede adaptation.

Challenges with surveying rural populations require innovative survey approaches superseding conventional mail, web-based, and telephone techniques (Dillman 2016). Thus, to ensure participatory research protocols could be followed, we determined that in-person survey recruitment was most appropriate. Subsequently, we administered the survey during the second (2016) and third (2017) of five annual Native Waters on Arid Lands Tribal Summits conducted within the study area. Recruitment for survey participation targeted voluntary summit attendees during plenary sessions where summit organizers scheduled time on the agenda to allow for participation in this research. We recruited participants to respond to the survey questions based upon their individually perceived needs, rather than responding on behalf of the Indigenous community in which they live and/or work. This recruitment protocol ensured that survey respondents self-identified as having some role or interest in community-based climate adaptation on reservation lands and acknowledged that only tribal governments can designate representatives to speak about official priorities. Attendees were also encouraged to bring copies of the survey back to their community members and coworkers to submit at a later date in an attempt to encourage participation outside of the summit; these responses make up less than $10 \%$ of the total responses. Over the two years of survey administration, a total of 98 participants completed survey questionnaires. Responses to the questions serve as the data sources for the study.

Of the 98 total respondents, the significant majority $(n=85)$ self-reported as either living or working on one or more of the reservations within the designated study area. That is, $45 \%(n=44)$ of respondents reported living and/or working in the Great Basin, $21 \%$ $(n=21)$ live in the Lower Colorado River region, and 18\% $(n=18)$ live in the Upper Colorado River region. This outcome ensures that the overall results reported here are representative of the target study area.

Additional respondent attributes are characterized by a majority of respondents selfreporting as Native American $(72 \%, \mathrm{n}=71)$; male $(70 \%, \mathrm{n}=69) ; 45$ years of age or older $(61 \%, \mathrm{n}=60)$; having post-secondary education $(83 \%, \mathrm{n}=81)$, and $55 \%$ specifically holding bachelor or graduate degrees $(n=54)$. Approximately $87 \%$ of respondents reported that they currently live on reservations $(n=85)$, with $52 \%(n=51)$ for more than 31 years, and $23 \%$ having lived on reservations for 30 years or less $(n=23)$. These results suggest the survey sample may not represent the demographic composition of the general population of Indigenous communities nationwide. Instead, the surveyed sample in this case represents the target population of tribal government employees, agriculturalists, researchers, and outreach professionals in the southwestern USA. That is, this study required participation from a stakeholder demographic who self-identified as being interested and/or involved in climate adaptation initiatives on reservation lands within the study area. Approximately $61 \%$ of respondents $(n=60)$ use climate science information/data in tribal agriculture, natural resource management, tribal college/university education, tribal government, or to teach tribal youth. Nearly half $(43 \%, \mathrm{n}=42)$ of respondents self-reported as working for tribal governments. When asked to rate the level of risk that climate uncertainty poses to tribal natural resources and communities, using a Likert-type scale where $1=$ none, $2=$ minor, $3=$ neutral, $4=$ major, and $5=$ extreme risk, the majority of respondents indicated that climate uncertainty poses either major $(56 \%, \mathrm{n}=53)$ or extreme $(29 \%, \mathrm{n}=28)$ risks. 


\subsection{Survey data analysis}

The analysis and results reported here feature 33 Likert-type scale questions that ask respondents to (1) prioritize their climate data and information needs and (2) identify their most frequently accessed sources of data and information specific to enhancing the climate resiliency of water resources on reservation lands. Part 1 of the survey includes 20 closed-ended question items intended to identify and prioritize information necessary for Indigenous communities to adapt to and plan for climate uncertainty. Each question provides a 5-point Likert-type rating scale of " 1 " indicating "very low priority," "2" indicating "low priority," "3" indicating "neutral" priority, "4" indicating "high priority," and a "5" indicating "very high priority." For the 20 question items, the question stem is: "To adapt to and plan for climate uncertainty, tribal communities need information about..." Of these 20 question items, 12 questions identify and prioritize information needs that support climate adaptation on reservation lands, six questions identify and prioritize specific data needs, and two questions assess individual preference for raw data collected as compared to generalized reports and/or data summaries.

Part 2 of the survey includes 13 question items that ask participants to rate the frequency in which they access climate adaptation planning information from the sources listed. Each closed-ended question provides a 5-point Likert-type scale rating of "1" indicating this resource is "never accessed," "2" indicating "rarely accessed, " 3 " indicating "occasionally accessed," "4" indicating "often accessed," and a " 5 " indicating "very often accessed." The stem for these 13 question items is: "In climate adaptation planning, we are currently using information provided by...".

Cronbach's coefficient alpha (CCA) was used to estimate internal consistency of the 33 Likert-type scale question items developed to assess climate information and data needs and frequency of access. The CCA score was high for each of three sets of questions (totaling 33 question items). For the 12 question items on climate information needs, $r=0.897$; for the six question items on climate data types, $r=0.921$; and for the 13 questions on frequency of access to climate information sources, $r=0.860$. These scores indicate high internal consistency, or reliability, among these three sets of question items (Carmines and Zeller 1979). For the two questions on preference for raw data as compared to generalized reports, $r=0.754$. This $r$-value indicates less internal consistency, but this may be associated with this calculation only being based on two question items.

In order to identify and prioritize survey participants' data and information needs, mean scores were calculated and ranked from highest to lowest priority. A ranking of mean scores reveals respondents' prioritized climate data and information needs relative to others. That is, the lowest ranked climate information item does not necessarily indicate an overall "very low priority" rating for that item, but rather indicates its priority standing relative to other climate information and data items identified for this assessment. We followed a similar procedure to identify and rank the most frequently accessed climate data/information resources. Mean scores were calculated and ranked for each of the 13 Likert-type questions on data/information resources from most frequently accessed to least frequently accessed.

Demographic information was also collected, and three aggregated variables were produced from these data to cross-analyze participant priorities based on their demographic differences. The aggregated variables reported here include water resource region (Great Basin, Colorado River Basin, and other) based on geographic location, 
role in climate adaptation initiatives (administration, implementation, and research) based on occupation, and educational attainment level (high school or less, some college or associate degree, bachelor degree, or professional or doctoral degree) based on highest degree completed, as these are meaningful and defensible demographic characteristics that might influence respondents' prioritized climate data and information needs. We intentionally avoided parsing out data by tribal affiliation. Doing so makes an erroneous assumption that tribal affiliation alone-separate from the cultural, economic, geographical, political, governmental, or numerous other diverse characteristics that comprise these communities-is a sufficient basis for reasonable comparisons between data and information priorities. Additionally, without official consent from each tribal government located within our study area, we would risk misrepresenting the perceptions of individual study participants as representative of sovereign tribal entities (Harding et al. 2012).

All participants consented to participate in this research, per human subject data collection procedures approved by the authors' Institutional Review Board. This study protects the anonymity of each individual research participant, which includes their voluntary consent to participate in this study. Our approved research protocol ensured that only deidentified data be collected, analyzed, and aggregated to protect individual and community anonymity.

\subsection{Ongoing engagement with participants}

Researchers who implement participatory research methods understand the importance of sharing research processes and findings with participants regularly and in a format that emphasizes transparency, respects local culture and knowledge, and ultimately improves research accountability (Datta et al. 2015; Glass et al. 2018). Preliminary and final assessment results were shared with study participants through oral presentations at professional meetings of tribal employees and members pursuing climate adaptation planning in their communities, in addition to hard copies of a summary extension outreach publication to be disseminated to the governmental departments of the participating tribes within the study region (Fillmore and Singletary 2021). Following participatory research principles and best practices, such as these, can enhance the capacity of scientific inquiry to meet the needs of Indigenous communities in pursuit of community-based adaptation pathways (Campos et al. 2016; Singletary and Sterle 2020). In developing this study, we built upon decades of prior work with Indigenous communities in this region, adapting our collaborative partnerships to better meet their needs as identified and/or requested.

\section{Results}

\subsection{Information and data needs}

Table 1 displays the calculated ranked mean scores of prioritized climate information needs to support adaptation on reservation lands, while Fig. 2 depicts response frequencies for each question item. In addition to calculating and ranking mean scores, survey responses were cross-correlated with aggregated variables based on self-identified demographics using a Chi-square test for statistical significance. Correlated variables with a $95 \%$ 


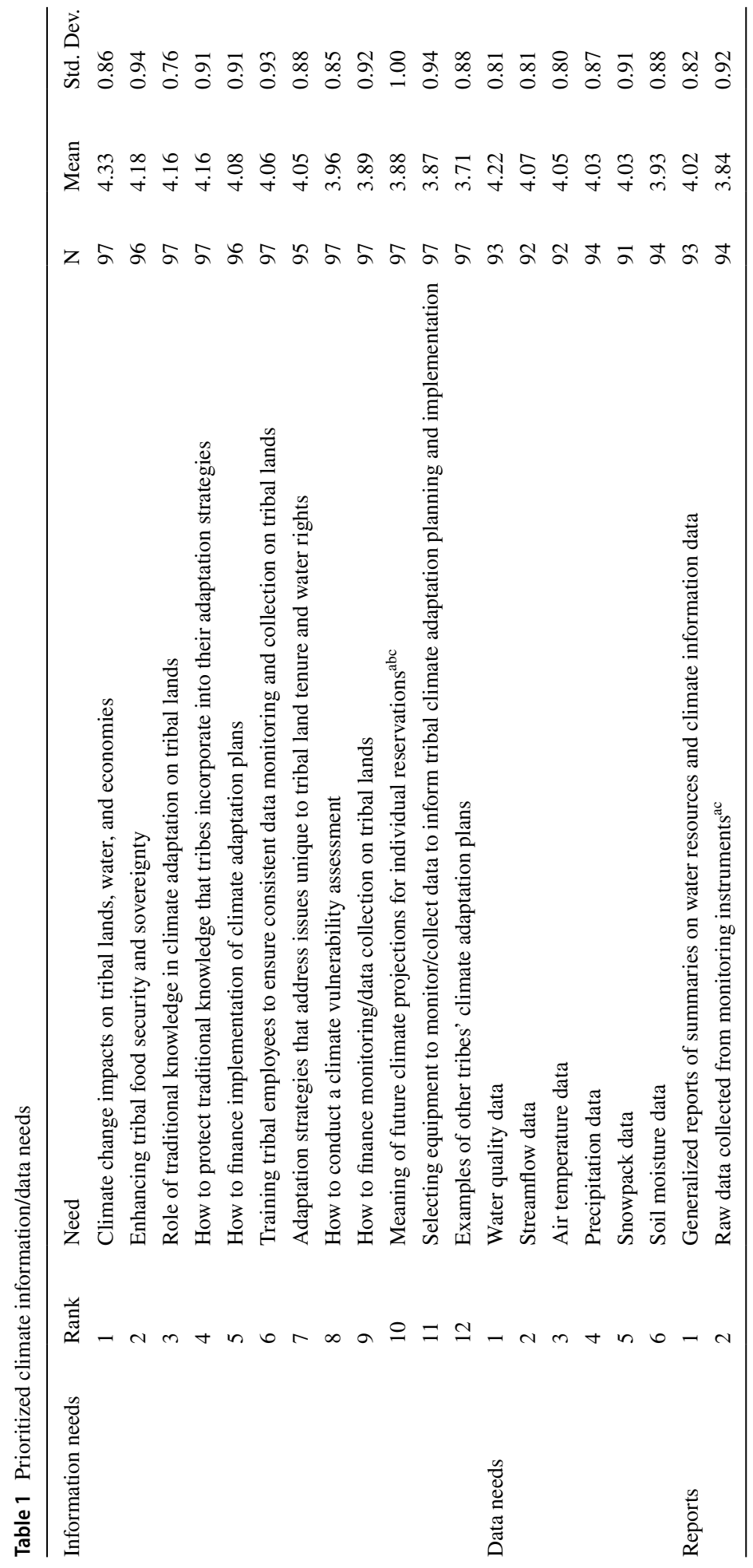




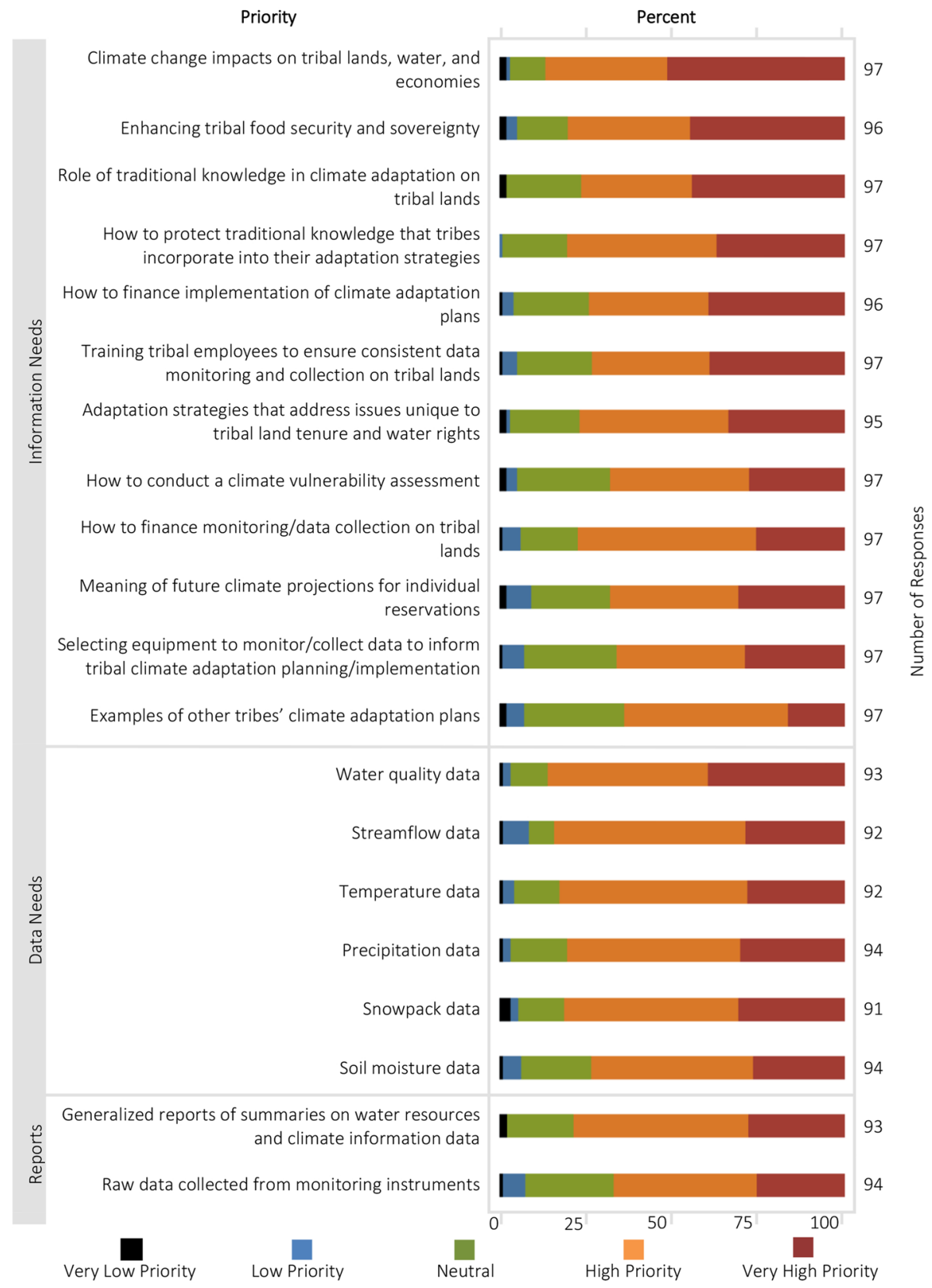

Fig. 2 Climate information and data ranked priorities 
Table 2 Most frequently accessed climate data and information resources

\begin{tabular}{|c|c|c|c|c|}
\hline Rank & Source & $\mathrm{N}$ & Mean & Std. Dev \\
\hline 1 & Tribal natural resource/water/land departments & 90 & 3.74 & 1.10 \\
\hline 2 & USGS Stream Gauges & 91 & 3.41 & 1.16 \\
\hline 3 & $\begin{array}{l}\text { National Oceanic Atmospheric Administration (NOAA); } \\
\text { National Weather Service; NRCS Snotel }\end{array}$ & 91 & 3.36 & 1.13 \\
\hline 4 & Tribal oral histories & 91 & 3.30 & 0.99 \\
\hline 5 & Traditional knowledge holders & 90 & 3.29 & 1.03 \\
\hline 6 & Tribal farmers and ranchers ${ }^{\mathrm{b}}$ & 92 & 3.20 & 1.14 \\
\hline 7 & Colleges and universities ${ }^{\mathrm{abc}}$ & 90 & 3.19 & 1.16 \\
\hline 8 & Tribally owned and operated monitoring equipment & 88 & 3.18 & 1.25 \\
\hline 9 & Native Waters on Arid Lands Tribal Summits ${ }^{\mathrm{b}}$ & 89 & 3.12 & 1.19 \\
\hline 10 & USDA climate hubs & 91 & 2.99 & 1.13 \\
\hline 11 & The Weather Channel; Weather.com; local news and radio & 91 & 2.96 & 1.17 \\
\hline 12 & Bureau of Indian Affairs climate planning program & 90 & 2.90 & 1.18 \\
\hline 13 & Tribal colleges and universities & 90 & 2.64 & 1.26 \\
\hline
\end{tabular}

or greater confidence interval (a $p$-value less than or equal to 0.05 ) are noted along with the ranked mean scores in Table 1 and Table 2. Overall, the priority rankings assigned by respondents held regardless of demographic characteristics.

Topics are ranked first by highest mean score $(5=$ very high priority) to lowest mean score $(1=$ very low priority), and then by lowest standard deviation (i.e., mean value with lowest associated distribution/error).

Superscripts represent priorities with statistically-significant association to one of the following aggregated demographic variables determined using a 95\% confidence interval (p-value of less than or equal to 0.05):

${ }^{a}$ Water resource region (based on geographic location): Great Basin, Colorado River Basin, or other.

${ }^{\mathrm{b}}$ Stakeholder role (based on occupation): administration, implementation, or research.

${ }^{c}$ Educational attainment level: high school or less, some college or associates degree, bachelor degree, professional degree or doctorate.

The top prioritized information need $(m=4.33, n=97)$ is "Climate change impacts on tribal lands, water, and economies." This result is not surprising considering that tribal leaders on reservation lands have repeatedly voiced the need for climate impact assessments as a critical first step to resiliency planning for their communities (National Congress of American Indians 2017). Of the 49 Indigenous communities included in the study area, nearly half $(44.89 \%)$ are undertaking efforts to assess climate impacts and develop climate adaptation plans for their communities, lands, and/or resources (Jantarasami et al. 2018).

The second ranked information need $(m=4.18 ; n=96)$ is, "Enhancing tribal food security and sovereignty." This finding is not surprising as water scarcity characterizes and has posed a chronic threat to the viability of conventional irrigated agriculture in the region. Most reservations in the region have suffered these effects in part as a result of inadequate water delivery infrastructure and unresolved water rights claims (Cosens 2012; Cosens and Chaffin 2016; McNeeley 2017). Both of which must be addressed to sustain water 
conserving agricultural production, which is paramount to attaining both food security as well as providing economic stability.

While the third and fourth ranked information needs have equivalent mean scores ( $m=4.16 ; n=97$ respectively), the item with a smaller standard deviation (0.76 as compared with 0.91) is ranked higher. These information needs include the "Role of traditional knowledge in climate adaptation on tribal lands" and "How to protect traditional knowledge that tribes incorporate into their adaptation strategies." The high priority ratings assigned to these topics indicate that survey respondents highly value the role of Indigenous traditional knowledge in climate adaptation. This response may also demonstrate the need to enhance tribal efforts to apply this knowledge in climate adaptation planning. To appropriately apply traditional knowledge to climate adaptation efforts requires the leadership of Indigenous community members who are both familiar with the knowledge itself, its level of sensitivity to outside exposure, and its relationship to climate adaptation (Klenk et al. 2017; Kovach 2010). Using and sharing this knowledge typically require securing prior and informed consent from the pertinent tribal governing body to permit the use of such knowledge and, therefore, its potential dissemination (Maldonado et al. 2016). This step is imperative as tribes increasingly develop, and many already possess, legal protections to address the misappropriation and abuse of traditional knowledge (Brewer and Kronk Warner 2015; Harding et al. 2012; Savaresi 2018).

As previously mentioned, the remaining information topics listed maintain high overall priority ratings. That is, mean scores range from 3.71 to 4.08 . In general, these topics include information to assist with building the fiscal and professional capacity of Indigenous communities to carry out climate adaptation activities. Due to the high standard deviation values, these topics may very well be higher in priority. Future partnering efforts to assist with capacity building of Indigenous communities should encourage collaboration and maintain space for Indigenous partners to co-identify project goals and priorities.

Of the types of climate data identified in this survey, respondents rated water quality data needs as their highest priority $(m=4.22 ; n=93)$ with a 0.15 -point difference in mean score between this top-rated need and the second ranked need, streamflow data $(m=4.07$; $n=92)$. For the remaining data types featured here, temperature ranked third $(m=4.05$; $n=92)$, followed by precipitation ranked as fourth $(m=4.03$; s.d. $=0.87 ; n=94)$, snowpack data as fifth $(m=4.03 ;$ s.d. $=0.91 ; n=91)$, and soil moisture data ranked last comparatively $(m=3.93 ; n=94)$.

The cross-correlation analysis between the three demographic variables-water resource region, stakeholder role, and educational attainment level—and information and data needs resulted in statistically significant correlations of only two priorities. Participant groups within all three variables disproportionately prioritized the information need, "Meaning of future climate projects for individual reservations." Participants in different water resource regions and in educational attainment level groups disproportionately prioritized the report need, "raw data collected from monitoring instruments".

\subsection{Accessing data/information resources}

Table 2 reports the most frequently accessed data and information resources. For mean scores that are the same, we use the standard deviation, or variance from the mean, to determine the higher ranked item. Response frequencies to each question item are depicted in Fig. 3. 


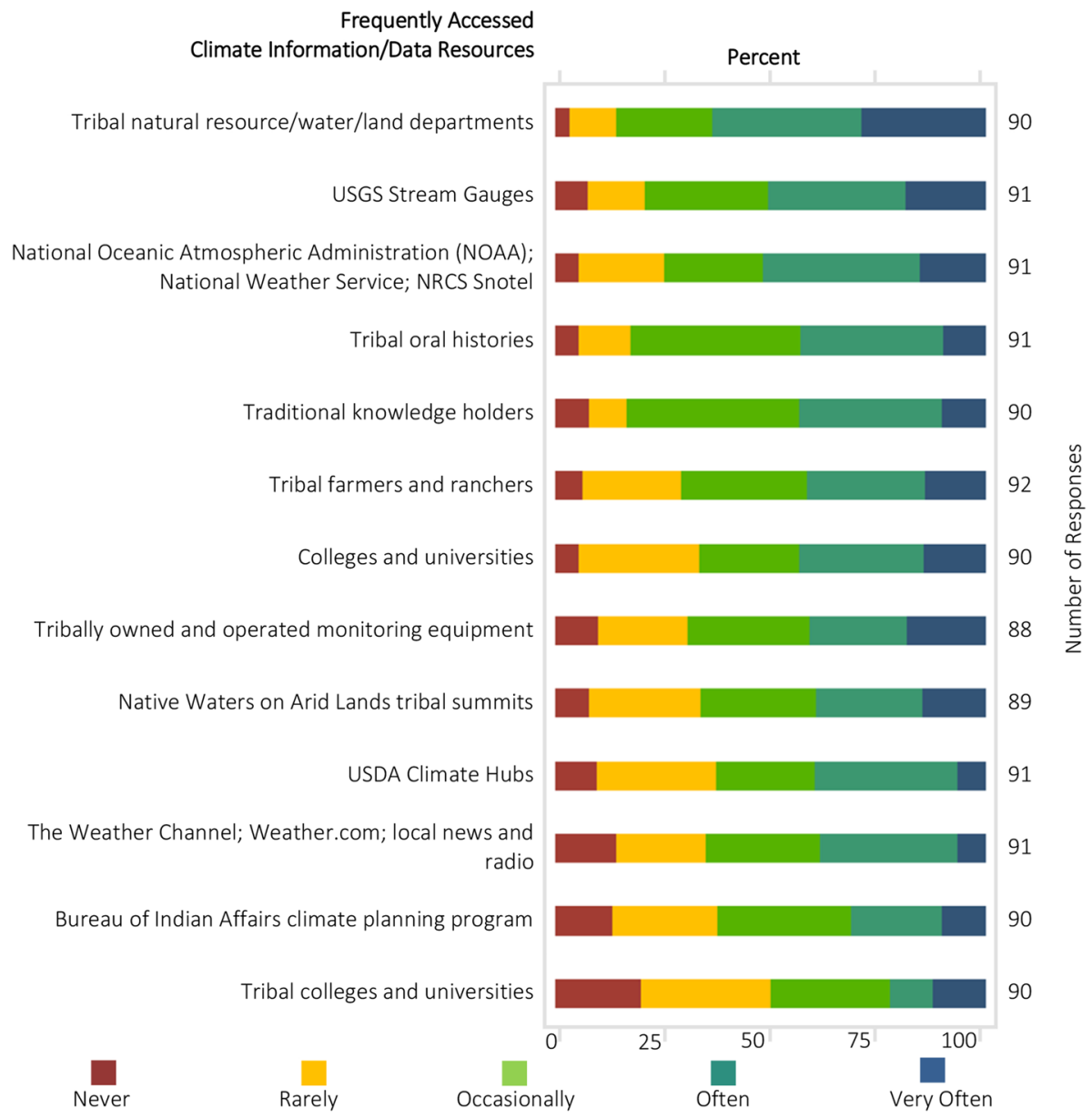

Fig. 3 Frequently accessed climate information and data sources

Topics are ranked by highest mean score $(5=$ very often accessed) to lowest mean score $(1=$ never accessed). Verbiage reported here is taken directly from the survey instrument. Sources specified as "tribal" here are referenced as "Indigenous" in the body of this study.

Superscripts represent priorities with statistically-significant association to one of the following aggregated demographic variables determined using a 95\% confidence interval ( $p$-value of less than or equal to 0.05 ):

${ }^{\mathrm{a}}$ Water resource region (based on geographic location): Great Basin, Colorado River Basin, or other.

${ }^{\mathrm{b}}$ Stakeholder role (based on occupation): administration, implementation, or research.

${ }^{c}$ Educational attainment level: high school or less, some college or associates degree, bachelor degree, professional degree or doctorate.

Understanding respondents' sources for climate data and information is an important component in assessing climate adaptation needs. Results can help to identify ways to improve tribes' access to and use of information sources commonly used by other organizations to support their adaptation initiatives. Our survey results indicate that respondents 
accessed most frequently $(m=3.74 ; n=90)$ their respective "Tribal natural resource/water/ land departments" for climate data and information. This result may demonstrate the important role that local resources are for Indigenous communities.

The second ranked resource currently accessed is "USGS stream gauges" $(m=3.41$; $n=91$ ). This result supports previous findings reported for climate data needs (see Table 2) where the second most prioritized item is streamflow data. The next information source ranked closely together is National Oceanic Atmospheric Administration/National Weather Service/National Resources Conservation Service (NOAA/NWS/NRCS) ( $m=3.36$; $n=91$ ). This source includes climate data collected and reported by the National Oceanic and Atmospheric Administration, National Weather Service, and Natural Resources Conservation Service and includes daily, monthly, and annual records for air temperature, precipitation amounts and types, and snow water estimates. While specific data types for water, climate, and environmental data and information may vary by individual use, the items featured in the survey instrument are verified as publicly available and can be used to help conduct climate assessments and/or informing adaptation initiatives.

Respondents also ranked informal information exchanges highly, which include sources such as tribal oral histories $(m=3.30, n=91)$, traditional knowledge holders $(m=3.29$, $n=90)$, and tribal farmers and ranchers $(m=3.20 ; n=92)$. Oral histories can include both local knowledge such as family history and environmental observations over an individual's lifetime. Traditional knowledge, such as traditional land use practices, can inform and/ or support climate adaption. Indigenous community members transfer information regularly, usually through informal conversations, and this information is relatively easy for Indigenous community members to obtain. These types of information sharing between Indigenous community members may also have positive impacts on mental and spiritual health of those involved (Burnette et al. 2020). While such information may not always be documented formally, it remains readily available, and based on these results, it appears to be used regularly. It is imperative, however, that adaptation efforts on reservation lands develop and recognize local protocols for integrating traditional knowledge within formal adaptation frameworks.

By descending order of mean scores, the next cluster of frequently accessed information and data sources include colleges and universities $(m=3.19 ; n=90)$; tribally-owned and operated weather monitoring equipment $(m=3.18, n=88)$; and Native Water on Arid Lands Annual Tribal Summits $(m=3.12 ; n=89)$. The least frequently accessed climate data and information sources are the USDA climate hubs $(m=2.99 ; n=91)$; weather channel and local news $(m=2.96 ; n=91)$; Bureau of Indian Affairs climate planning program $(m=2.90 ; n=90)$, and tribal colleges and universities $(m=2.64 ; n=90)$. These mean scores indicate that respondents only "rarely" to "occasionally" access these sources of climate data and information.

The cross-correlation analysis between the three demographic variables and frequently accessed climate data and information sources resulted in statistically significant correlations between only three sources. Participant groups within all three variables disproportionately access "colleges and universities." Participants in different stakeholder roles disproportionately access, "Tribal farmers and ranchers," and the "Native Waters on Arid Lands Tribal Summits." 


\section{Discussion}

Water quality being the highest rated data need was initially a surprising result. This finding being of such a high priority may be attributed to the disproportionate water quality disparities impacting Indigenous communities on reservation lands in comparison to non-Indigenous populations in the USA (Conroy-Ben and Richard 2018). Compared to the other data types featured in this assessment, water quality data are the least readily available through the USGS online data portal for the southwestern USA. The USA Environmental Protection Agency (EPA) is tasked with enforcing provisions of the Clean Water Act, to monitor point source pollutants and non-point source pollutants, and is charged with overseeing water quality monitoring, assessment, and reporting in waterbodies that impact human health (Federal Water Pollution Control Act Amendments 1972). These water quality data, however, are limited in scope to inform water management decisions. That is, water quality data collection and analysis are labor intensive, and due to the multitude of external influences on water quality, it is unreasonable to extrapolate single point collections as being representative of regional conditions.

Further, quantifying climate impacts on water quality at a regional scale is a complex process. Unlike climate data, such as temperature and precipitation, which have regional and even global relationships, water quality can be particularly site specific. This is why water quality standards are defined differently for different bodies of water. Standards are typically dependent on the location, purpose, use, and/or accessibility of the water to the public and are often re-evaluated and changed over time (Xia et al. 2015). In much of the western USA, water quality standards are set by regional water quality control boards to remain in compliance with federal EPA standards, but there are still rural watersheds that lack the baseline data needed to set standards. Without baseline data, or data collected throughout time, it is challenging to understand relationships between water quality and climate, yet alone predict changes.

Another surprising finding from this analysis (see Table 2) is that respondents ranked snowpack data fifth in priority. For the snow-fed basins that comprise our study area, planning effectively for summer water availability requires earlier and accurate predictions of water equivalent stored in winter snowpack (Fritze et al. 2011; Oubeidillah et al. 2011; Seager et al. 2013). A comparatively lower ranking for this item may indicate a need for outreach education concerning the use of snowpack data to predict summer water availability. In contrast, it may also suggest that respondents recognize that this annual water supply predictor is increasingly variable or in decline.

Another informative finding here is that survey respondents revealed a clear preference for "Generalized reports of summaries on water resources and climate information data" ( $m=4.02, n=93)$ as compared to "Raw data collected from monitoring instruments" ( $m=3.84, n=94)$ as evidenced by 0.18 -point difference in mean scores between the two items (see Table 1). This preference may indicate lack of time and/ or available human resources necessary to collect, process, and summarize raw data, and report it in a timely and consistent manner so as to be useful to community-based adaptation planning and implementation. Additionally, this finding may speak to an issue of data and information accessibility. That is, publicly funded climatological research typically makes data publicly available through online databases; however, if publicly available data are not in a format that practitioners and general members of the public can easily use to inform their decisions, then it is not publicly accessible. 
Researchers aiming to support local climate adaptation action in Indigenous communities should factor in these limitations and aim to provide more easily accessible modes of critical data and findings to facilitate broader use of this information.

\section{Conclusion}

The persistence of Indigenous communities in a region characterized by historical climate extremes and water scarcity implies that climate resilience is an inherent part of their cultures and economies, which should encourage locally led community-based climate adaptation efforts (Chief 2020; McNamara et al. 2020). Integrating traditional knowledge and values into adaptation strategies may be particularly advantageous and perhaps a continuance of sustainable practices that have persisted and endured within these communities for thousands of years (Chief et al. 2016; Gautam et al. 2013; Robitaille et al. 2017; Whyte 2018a, b). Findings from this study demonstrate this strategy as a high priority. Coupling this finding with the result that tribal natural resource departments are the most readily accessed sources of climate data and information suggests that Indigenous communities already have many tools to support localized adaptation planning and action independently. Researchers and scientists may still assist localized efforts to enhance the climate resiliency of Indigenous communities, as results from this study suggest that climate information and data are not universally available or accessible to all communities. Results also suggest there may be a need to more effectively communicate and disseminate climate data and information among Indigenous communities increasing the coherence of climate research and adaptation priorities across local, regional, and national scales. Specifically, these assessment results can inform and strengthen applied climate adaptation research and educational outreach across the southwestern USA with implications for improving climate adaptation self-determination of Indigenous communities elsewhere.

\subsection{Study limitations}

We maintain that our survey sample reasonably represents our target population given that it includes practitioners from multiple universities, federal agencies, and the Indigenous communities within the study region (Fowler 2014). With respect to community-based adaptation initiatives, however, our surveyed population includes a subset of community members primarily comprised of natural resource management and similar professionals. While surveying an expert population is helpful for identifying climate data and information needs, expanding this study to include a more diverse and intergenerational range of community members may yield additional important findings. A larger sample size will also improve this study as a small sample size makes it challenging to identify statistical significance or to determine causal relationships using these survey data (Dillman 1978). For example, ranking information and data needs using mean scores produces a list of priorities, but most mean scores are associated with sizeable standard deviations. A larger number of survey respondents is necessary to test the extent to which the current mean score rankings are upheld.

While primary data collection during a regional tribal climate summit setting facilitated a convenience sampling strategy, the sample population may not be entirely representative of community-based climate adaptation practitioners working on reservation lands in 
the region. That is, summit attendance required funding for registration and travel, which may have limited the participation of early career tribal professionals, students, and/or other Indigenous community members interested or active in climate adaptation on their respective lands. We attempted to overcome this by requesting that participants bring surveys back to their communities, but those responses represented less than $10 \%$ of the overall sample. Considering this study is focused specifically on climate data and information needs on reservations in the region, having a target population of practitioners representing Indigenous communities within the region was reasonable. And results from this study represent a focused subset of priorities for climate adaptation planning on these reservation lands. Additional research at more localized scales is needed to assess a broader scope of climate impacts, priorities, and opportunities for Indigenous communities in this region.

\subsection{Future research}

Replication of this assessment, combining both face-to-face and e-survey administration, may inform the potential study limitations cited here. Such additional research may ensure that assessment results more accurately represent a future generation of Indigenous stakeholders working on reservation lands, which may better capture localized Indigenous community needs. Nevertheless, this exploratory study comprises a critical first step in building a better understanding of information and data needs that, if effectively addressed, may enhance climate resiliency on reservation lands in the southwestern USA. Methods and results reported here may help guide scientists interested in engaging with Indigenous communities to support their ongoing climate adaptation research, planning, and action efforts.

Based on these survey results, it is uncertain if respondents are primarily concerned with the general limited availability of water quality data or the impacts of climate change on water quality. A more in-depth follow-up survey is needed to more thoroughly assess priorities related to this data and/or information need. That is, priorities may range from climate impacts on baseline water quality standards, drinking water quality, water quality for agriculture, groundwater quality, and/or riparian water quality needed to support ecosystem services. Increasingly, Indigenous communities request future research to focus on the effects of climate change specific to water quality (Chief 2020; Jantarasami et al. 2018).

The very purpose for conducting this assessment is to help Indigenous communities to identify and prioritize such needs, which may include ongoing climate science research, increased allocation of fiscal resources, and increased outreach education, among other forms of capacity-building on reservation lands. Results from this needs assessment suggest that those individuals who responded to this survey and who are engaged in community-based adaptation initiatives on reservation lands in the southwestern USA perceive that climate information and data resources are currently limited despite having many tools and resources to support adaptation efforts such as access to traditional knowledge holders. As such limitations may hinder comprehensive assessments of local climate impacts on reservation lands, Indigenous communities may likewise wish to increase collaborative partnerships with federal and state government agencies, universities, and non-profit organizations to bolster; at least in the short run, tribal self-determination efforts to realize their respective community-based adaptation goals. These collaborative efforts should empower Indigenous communities to lead their own community-based adaptation initiatives respective to their communities and mutually respect the various roles that different practitioners and knowledge holders can contribute to these processes to ensure beneficial outcomes. 
In the long run, increasing the numbers of Indigenous students and subsequently scholars pursuing climate science research and outreach with Indigenous communities will organically enhance the tribal self-determination of climate resiliency on reservation lands, and such knowledge will likely extend beyond the borders of reservations to enhance the climate resiliency of communities elsewhere (Chief 2020; Kozich et al. 2018). At the same time, Indigenous communities should continue to take necessary steps to ensure data sovereignty, including voluntary participation in community-based adaptation research and implementation projects. This includes ongoing efforts to establish research protocols when working with tribes and the protection of sensitive traditional knowledge from misuse that could inadvertently harm tribal nations (Ellis and Perry 2020; Whyte 2018a, b). Finally, future research must continue to evaluate the impacts of participatory research and development practices at local, regional, national, and international scales and should aim to support locally led community-based adaptation efforts rather than extract knowledge or resources from historically marginalized populations including Indigenous communities (McNamara et al. 2020; McNamara and Buggy 2017; Dodman and Mitlin 2013).

Acknowledgements The authors acknowledge participants of the Native Waters on Arid Lands Tribal Summits (2015-2017) who contributed substantively to this study. This research is funded by the U.S. Department of Agriculture National Institute of Food and Agriculture Water for Agriculture Challenge Area Award Number 2015-69007-23190 “Enhancing climate resiliency and agriculture on American Indian lands."

Author contribution Helen Fillmore and Loretta Singletary contributed equally to the study conception, design, and material preparation. Helen Fillmore led in the data collection and analysis. Both authors contributed equally to the first draft of the manuscript and all subsequent versions and revisions. Both authors read and approved the final manuscript.

Funding This research is funded by the U.S. Department Availability of data and material

Data Availability As this research involves surveying the opinions of human subjects, data will be kept and stored following the University of Nevada, Reno Institutional Review Board guidelines for which this research was approved.

Code availability Not applicable.

\section{Declarations}

Ethics approval This research protocol was reviewed and approved by the University of Nevada, Reno Office of Research Integrity Internal Review Board.

Consent to participate Voluntary completion of survey questionnaire indicated consent to participate as part of the approved survey recruitment protocol.

Consent for publication Voluntary completion of survey questionnaire indicated consent to publish research findings as part of the approved survey recruitment protocol.

Conflict of interest/Competing interests.

The authors declare no competing interests.

Open Access This article is licensed under a Creative Commons Attribution 4.0 International License, which permits use, sharing, adaptation, distribution and reproduction in any medium or format, as long as you give appropriate credit to the original author(s) and the source, provide a link to the Creative Commons licence, and indicate if changes were made. The images or other third party material in this article are included in the article's Creative Commons licence, unless indicated otherwise in a credit line to the material. If material is not included in the article's Creative Commons licence and your intended use is not permitted by statutory regulation or exceeds the permitted use, you will need to obtain permission directly from the copyright holder. To view a copy of this licence, visit http://creativecommons.org/licenses/by/4.0/. 


\section{References}

Bennett TMB, Maynard NG, Cochran P, Gough R, Lynn K, Maldonado J, Voggesser G, Wotkyns S, Cozzetto K (2014) Ch. 12: Indigenous peoples, lands, and resources. Climate Change Impacts in the United States: The Third National Climate Assessment 297-317. https://doi.org/10.7930/J09G5JR1

Brewer JP II, Kronk Warner KA (2015) Protecting Indigenous knowledge in the age of climate change. Georgetown Int Environ Law Rev 27(4):585-628

Burnette CE, Clark CB, Rodnin CB (2019) "Living off the land": How subsistence promotes well-being and resilience among Indigenous peoples of the Southeastern United States. Soc Serv Rev 92(3):369-400. https://doi.org/10.1086/699287

Burnette CE, Lesesne R, Temple C, Rodning CB (2020) Family as the conduit to promote Indigenous women and men's enculturation and wellness: "I wish I had learned earlier." J Evid-Based Soc Work 17(1):1-23. https://doi.org/10.1080/26408066.2019.1617213

Campos IS, Alves FM, Dinis J, Truninger M, Vizinho A, Penha-Lopes G (2016) Climate adaptation, transitions, and socially innovative action-research approaches. Ecol Soc 21(1):13. https://doi.org/10.5751/ ES-08059-210113

Carmines EG, Zeller RA (1979) Reliability and validity assessment. Sage Publications, Beverly Hills

Chief K (2020) Water in the native world. J Contemp Water Res Educ 169:1. https://doi.org/10.1111/j.1936704X.2020.03328.x

Chief K, Daigle JJ, Lynn K, Whyte KP (2014) Indigenous experience in the U.S. with climate change and environmental stewardship in the Anthropocene. U.S. Department of Agriculture, Forest Service RMRS-P-71: 161-176. https://www.fs.usda.gov/treesearch/pubs/46584. Accessed 6 June 2020

Chief K, Meadow A, Whyte K (2016) Engaging southwestern tribes in sustainable water resources topics and management. Water 8(8). https://doi.org/10.3390/w8080350

Climate and Traditional Knowledges Workgroup (2014) Guidelines for considering traditional knowledges in climate change initiatives. http://climatetkw.wordpress.com/. Accessed 10 Nov 2020

Cochran P, Huntington OH, Pungowiyi C, Tom S, Chapin FS III, Huntington HP, Maynard NG, Trainor SF (2013) Indigenous frameworks for observing and responding to climate change in Alaska. Clim Change 120(3):557. https://doi.org/10.1007/s10584-014-1187-z

Colby B, Thorson J, Britton S (2005) Negotiating tribal water rights: fulfilling promises in the arid West. University of Arizona Press, Tucson

Conroy-Ben O, Richard R (2018) Disparities in water quality in Indian Country. J Contemp Water Res Educ (163)1: 31. https://doi.org/10.1111/j.1936-704X.2018.03268.x

Cosens B, Chaffin B (2016) Adaptive governance of water resources shared with Indigenous Peoples: The role of law. Water 8(3):97. https://doi.org/10.3390/w8030097

Cosens B (2012) The legacy of Winters v. United States and the Winters Doctrine, one hundred years later. In: Cosens B, Royster JV (eds) The future of Indian and federal reserved water rights: The Winters centennial. University of New Mexico Press, Albuquerque

Cozzetto K, Chief K, Dittmer K, Brubaker M, Gough R, Ettawageshi F, Wotkyns S, Opitz-Stapleton S, Duren S, Chavan P (2013) Climate change impacts on the water resources of American Indians and Alaska Natives in the U S. Clim Change 120(3):569-584. https://doi.org/10.1007/s10584-013-0852-y

Credo J, Torkelson J, Rock T, Ingram JC (2019) Quantification of elemental contaminants in unregulated water across western Navajo Nation. Int J Env Res Public Health 16(15):2727. https://doi.org/10.3390/ ijerph16152727

Datta R, Khyang NU, Khyang HKP, Kheyang HAP, Khyang MC, Chapola J (2015) Participatory action research and researcher's responsibilities: an experience with an Indigenous community. Int J Soc Res Methodol 18(6):581-599. https://doi.org/10.1080/13645579.2014.927492

Deol S (2017) The effects of water quantification on tribal economies: evidence from the western U.S. Reservations. Master's Thesis, University of Arizona

Dillman DA (1978) Mail and telephone surveys: the total design method. Wiley, New York

Dillman DA (2016) Moving survey methodology forward in our rapidly changing world: a commentary. J Rural Soc Sci 31(3): 160-174. https://egrove.olemiss.edu/jrss/vol31/iss3/8

Dodman D, Mitlin D (2013) Challenges for community-based adaptation: discovering the potential for transformation. J Int Dev 25. https://doi.org/10.1002/jid.1772

Donatuto JL, Satterfield TA, Gregory R (2011) Poisoning the body to nourish the soul: prioritizing health risks and impacts in a Native American community. Health Risk Soc 13(2):103. https://doi.org/10. 1080/13698575.2011.556186

Elias EH, Flynn R, Idowu OJ, Reyes J, Sanogo S, Schutte BJ, Smith R, Steele C, Sutherland C (2019) Crop vulnerability to weather and climate risk: analysis of interacting systems and adaptation efficacy for sustainable crop production. Sustain 11(23):6619. https://doi.org/10.3390/su11236619 
Ellis R, Perry D (2020) A confluence of anticolonial pathways for indigenous sacred site protection. J Contemp Water Res Educ 169:8. https://doi.org/10.1111/j.1936-704X.2020.03329.x

Federal Water Pollution Control Act Amendments of 1972, Pub. L. 92-500, 86 Stat. 816 (1972)

Fillmore H (2017) Using the Washoe language to inform hydrologic and environmental models. Groundw 55(5):626-629. https://doi.org/10.1111/gwat.12571

Fillmore H, Singletary L (2021) Climate resilient tribal waters. Stakeholder perspectives on climate information and data needs to enhance the resiliency of water resources on reservation lands in the southwestern United States. University of Nevada, Reno, Ext Spec Pub 21(04).

Ford JD, Sherman M, Berrang-Ford L, Llanos A, Carcamo C, Harper S, Lwasa S, Namanya D, Marcello T, Maillet M, Edge V (2018) Preparing for the health impacts of climate change in indigenous communities: the role of community-based adaptation. Glob Environ Change 49:129. https://doi.org/10.1016/j. gloenvcha.2018.02.006

Fritze H, Stewart IT, Pebesma E (2011) Shifts in Western North American snowmelt runoff regimes for the recent warm decades. J Hydrometeorol 12(5):989-1006. https://doi.org/10.1175/2011jhm1360.1

Gautam, Chief, Smith (2013) Climate change in arid lands and Native American socioeconomic vulnerability: the case of the Pyramid Lake Paiute Tribe. Clim Change 120(3):585-599. https://doi.org/10.1007/ s10584-013-0737-0

Gettelsohn J, Belcourt A, Magarati M, Booth-LaForce C, Duran B, Mishra SI, Belone L, Jernigan VBB (2018) Building capacity for productive Indigenous community-university partnerships. Prev Sci 21:22-32. https://doi.org/10.1007/s11121-018-0949-7

Glass RD, Morton JM, King JE, Krueger-Henney P, Moses MS, Sabati S, Richardson T (2018) The ethical stakes of collaborative community-based social science research. Urban Educ 53(4):503-531. https:// doi.org/10.1177/0042085918762522

Gurney RM, Hamlet AF, Regan PM (2020) The influences of power, politics, and climate risk on US subnational climate action. Environ Sci Pol 116:96-113. https://doi.org/10.1016/j.envsci.2020.06.023

Harding A, Harper B, Stone D, O’Neill C, Berger P, Harris S, Donatuto J (2012) Conducting research with Tribal communities: sovereignty, ethics, and data-sharing issues. Environ Health Perspect 120(1):610. https://doi.org/10.1289/ehp.1103904

Hoerling M, Barsugli J, Livneh B, Eischeid J, Quan X, Badger A (2019) Causes for the century-long decline in Colorado River flow. J Clim 32(32):8181-8203. https://doi.org/10.1175/JCLI-D-19-0207.s1

Institute for Tribal Environmental Professionals (2020) U.S. Climate Resilience Tribal Climate Change Adaptation Planning Toolkit. Northern Arizona University. http://www7.nau.edu/itep/main/tcc/Resou rces/adaptation. Accessed 3 July 2020.

Jantarasami LC, Novak R, Delgado R, Marino E, McNeeley S, Narducci C, Singletary L, Raymond-Yakoubian J, Rowys Whyte K (2018) Tribes and Indigenous peoples. Impacts, Risks, and Adaptation in the United States: Fourth National Climate Assessment 2(15):572-603. https://doi.org/10.7930/NCA4. 2018.CH15

Kirkby P, Williams C, Huq S (2017) Community-based adaptation (CBA): adding conceptual clarity to the approach and establishing its principles and challenges. Clim Dev 10:577. https://doi.org/10.1080/ 17565529.2017.1372265

Klenk N, Fiume A, Meehan K, Gibbes C (2017) Local knowledge in climate adaptation research: moving knowledge frameworks from extraction to co-production. Wiley Interdiscip Rev-Clim Change 8(5):15. https://doi.org/10.1002/wcc.475

Kozich A, Halvorsen KE, Mayer AS (2018) Perspectives on water resources among Native and non-Native residents of the Great Lakes Region. J Contemp Water Res Educ 163:94. https://doi.org/10.1111/j. 1936-704X.2020.03329.x

Li DY, Wrzesien ML, Durand M, Adam J, Lettenmaier DP (2017) How much runoff originates as snow in the western United States, and how will that change in the future? Geophys Res Lett 44(12):61636172. https://doi.org/10.1002/2017gl073551

Long JW, Steel EA (2020) Shifting perspectives in assessing socio-environmental vulnerability. Sustain 12(7):2625. https://doi.org/10.3390/su12072625

MacDonald GM (2010) Water, climate change, and sustainability in the Southwest. Proc Natl Acad Sci US Am 107(50):21256-21262. https://doi.org/10.1073/pnas.0909651107

Maldonado J, Bennett TMB, Chief K, Cochran P, CozzettoGough KR, Hiza Redsteer M, Lynn K, Maynard $\mathrm{N}$, Voggesser G (2016) Engagement with Indigenous peoples and honoring traditional knowledge systems. Clim Change 135(1):111-126. https://doi.org/10.1007/s10584-015-1535-7

Martin C, Doyle J, LaFrance J, Lefthand MJ, Young SL, Three Irons E, Eggers MJ (2020) Change rippling through our waters and culture. J Contemp Water Res Educ 169:6. https://doi.org/10.1111/j.1936704X.2020.03332.x 
Mayer B, Joshweseoma L, Sehongva G (2019) Environmental risk perceptions and community health: arsenic, air pollution, and threats to traditional values of the Hopi Tribe. J Com Health 44:896-902. https:// doi.org/10.1007/s10900-019-00627-8

McNamara KE, Buggy L (2017) Community-based climate change adaptation: a review of academic literature. Local Environ 22(4):443. https://doi.org/10.1080/13549839.2016.1216954

McNamara KE, Clissold R, Westoby R, Piggott-McKellar AE, Kumar R, Clarke T, Namoumou F, Areki F, Joseph E, Warrick O, Nunn PD (2020) An assessment of community-based adaptation initiatives in the Pacific Islands. Nat Clim Chang 10:628. https://doi.org/10.1038/s41558-020-0813-1

McNeeley SM (2017) Sustainable climate change adaptation in Indian Country. Weather Clim Soc 9(3):393-404. https://doi.org/10.1175/WCAS-D-16-0121.1

Meadow AM, Ferguson DB, Guido Z, Horangic A, Owen G, Wall T (2015) Moving toward the deliberate coproduction of climate science knowledge. Weather Clim Soc 7(2):179-191. https://doi.org/10.1175/ wcas-d-14-00050.1

Miller OL, Putman AL, Alder J, Miller M, Jones DK, Wise DR (2021) Changing climate drives future streamflow declines and challenges in meeting water demand across the southwestern United States. J Hydro X 11(1). https://doi.org/10.1016/j.hydroa.2021.100074

Miller WP, Piechota TC (2011) Trends in western United States snowpack and related upper Colorado River Basin streamflow. J Am Water Resour Assoc 47(6):1197-1210. https://doi.org/10.1111/j.1752-1688. 2011.00565.x

National Congress of American Indians (2017) We are strong nations: 2016 - 2017 annual report. http:// www.ncai.org/resources/ncai_publications/2016-2017-annual-report-we-are-strong-nations. Accessed 23 January 2020

Oubeidillah AA, Tootle GA, Moser C, Piechota T, Lamb K (2011) Upper Colorado River and Great Basin streamflow and snowpack forecasting using Pacific oceanic-atmospheric variability. J Hydrol 410(34):169-177. https://doi.org/10.1016/j.jhydrol.2011.09.030

Petzold J, Andrews N, Ford JD, Hedemann C, Postigo JC (2020) Indigenous knowledge on climate change adaptation: a global evidence map of academic literature. Environ Res Lett 15(11):3007. https://doi. org/10.1088/1748-9326/abb330

Redsteer MH, Kelley KB, Francis H, Block D (2018) Accounts from tribal elders: increasing vulnerability of the Navajo people to drought and climate change in the southwestern United States. In: Nakashima D, Krupnik I, Rubis JT (eds) Indigenous knowledge for climate change assessment and adaptation. Cambridge University Press, pp 171-187. https://doi.org/10.1017/9781316481066.013

Reid H (2016) Ecosystem- and community-based adaptation: learning from community-based natural resource management. Clim Dev 8(1):4. https://doi.org/10.1080/17565529.2015.1034233

Robitaille PA, Shahi C, Smith MA, Luckai N (2017) Growing together: a principle-based approach to building collaborative Indigenous partnerships in Canada's forest sector. Forestry Chron 93(1):44-57. https://doi.org/10.5558/tfc2017-010

Savaresi A (2018) Traditional knowledge and climate change: a new legal frontier? J Hum Rights Environ 9(1):32-50. https://doi.org/10.4337/jhre.2018.01.02

Seager R, Ting M, Li C, Naik N, Cook B, Nakamura J, Liu H (2013) Projections of declining surfacewater availability for the southwestern United States. Nat Clim Change 3(5):482-486. https://doi.org/ $10.1038 /$ nclimate 1787

Singletary L, Sterle K (2020) Supporting local climate adaptation through knowledge co-production: outcomes from a collaborative modeling research project in the western United States Clim Serv 20 https://doi.org/10.1016/j.cliser.2020.100201

Smith WJ, Liu ZW, Safi AS, Chief K (2014) Climate change perception, observation and policy support in rural Nevada: A comparative analysis of Native Americans, non-native ranchers and farmers and mainstream America. Environ Sci Policy 42:101-122. https://doi.org/10.1016/j.envsci.2014.03.007

Stanley LR, Swaim RC, Keawe'aimoku Kaholokula J, Kelly KJ, Belcourt A, Allen J, (2017) The imperative for research to promote health equity in Indigenous communities. Prev Sci 21(1):13-21. https://doi. org/10.1007/s11121-017-0850-9

Steele C, Reyes J, Elias E, Aney S, Rango A (2018) Cascading impacts of climate change on southwestern US cropland agriculture. Clim Change 148:437-450

Thomas K, Hardy RD, Lazrus H, Mendez M, Orlove B, Rivera-Collazo I, Roberts JT, Rockman M, Warner BP, Winthrop R (2018) Explaining differential vulnerability to climate change: A social science review. Wires Clim Change 10(2):e565. https://doi.org/10.1002/wcc.565

Udall B, Overpeck J (2017) The twenty-first century Colorado River hot drought and implications for the future. Water Resourc Res 53(3):2404-2418

Westoby R, McNamara KE, Kumar R, Nunn PD (2020) From community-based to locally led adaptation: Evidence from Vanuatu. Ambio 49:1466-1473. https://doi.org/10.1007/s13280-019-01294-8 
Whyte KP (2018a) Indigenous science (fiction) for the Anthropocene: ancestral dystopias and fantasies of climate change crises. Environ Plan e: Nat Space 1:224. https://doi.org/10.1177/2514848618777621

Whyte KP (2018b) What do Indigenous knowledges do for Indigenous peoples. In: Nelson MK, Shilling $\mathrm{D}$ (eds) Keepers of the green world: traditional ecological knowledge and sustainability. Cambridge University Press, London, pp 57-82

Williams T, Hardison P (2013) Culture, law, risk and governance: contexts of traditional knowledge in climate change adaptation. Clim Change 120(3):531-544. https://doi.org/10.1007/s10584-013-0850-0

Xia XH, Wu Q, Mou XL, Lai YJ (2015) Potential impacts of climate change on the water quality of different water bodies. J Environ Inf 25(2):85-98. https://doi.org/10.3808/jei.201400263

Publisher's note Springer Nature remains neutral with regard to jurisdictional claims in published maps and institutional affiliations. 